\title{
THE RELATIONSHIP BETWEEN TIDAL VOLUME AND RESPIRATORY FREQUENCY DURING MUSCULAR EXERCISE
}

\author{
A. W. S. WATSON, M.Sc., F.R.A.M.I.
}

\section{Introduction}

The volume of air entering or leaving the lungs per minute may be increased either by increasing the number of breaths taken per minute or by increasing the volume of each breath or a combination of both. A large number of independent factors are responsible for the control of breathing and a number of investigators have reported that breathing frequency and depth may be driven independently by different mechanisms.

The relationship between breathing frequency and tidal volume is complicated by the existance of the respiratory dead space. Air is conducted to and from the lungs along the same set of tubes so that the first portion of any breath reaching the lungs is contaminated with expired air from the preceeding expiration. The volume of the dead space remains approximately constant so that its effect is most marked when the volume of each breath is small; the percentage of fresh air reaching the alveoli being lower. Thus although an infinite number of combinations of frequency and depth of breathing results in the same volume of air being inspired, they are not equivalent in terms of alveolar ventilation.

The development of new methods of investigating the relationship between the depth and frequency of breathing have lead to revision of some previously held ideas.

\section{The Respiratory Dead Space}

The volume of air expired per minute (expiratory minute volume, $\dot{v})$ is directly proportional to the frequency of breathing $(f)$ and the mean volume of air expired with each breath. (tidal volume $V_{T}$ ).

$$
\text { Thus } V_{e}=V_{T} \text {.f }
$$
by

Simularly the inspiratory minute volume $\left(V_{1}\right)$ is given

$$
V_{1}=V_{T . f}
$$

This is a superficially similar relationship to that for cardiac output (O) which is proportional to heartrate and stroke volume.

$$
\begin{aligned}
\text { Cardiac Output } & =\text { Stroke volume } \times \text { Heart rate } \\
\dot{Q}=S . V . & \times f_{H}
\end{aligned}
$$

However, the purpose of inspiring air is to allow gasous exchange with blood, a process which takes place in the alveoli. Since air enters and leaves the alveoli by the same set of tubes, a proportion of each tidal volume never reaches the alveoli but merely fills the unperfused air ways to be expelled again unchanged at the next expiration. The volume of the air ways is known as the anatomical dead space $\left(V_{D}\right)$ and the air reaching the alveoli per minute is known as the alveolar ventilation $\left(\dot{V}_{A}\right)$

The situation is illustrated in figure 1.

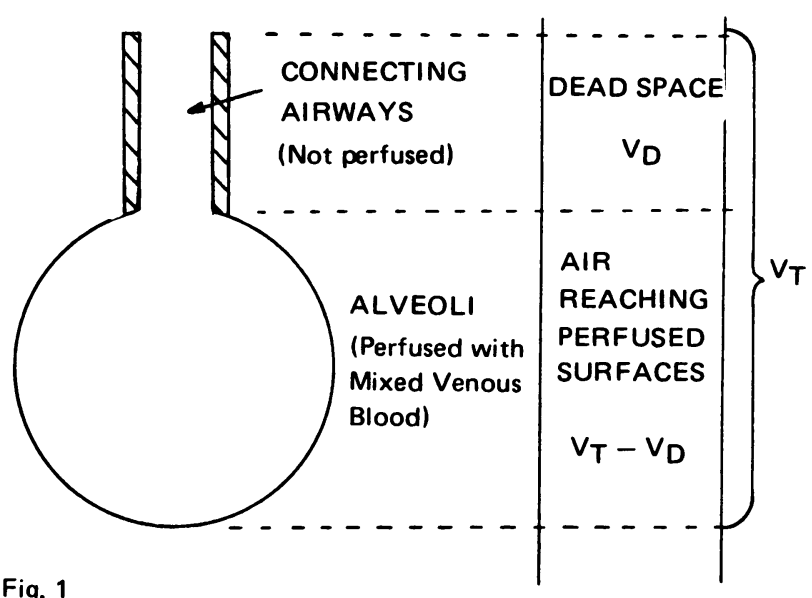

Fig. 1

For a single breath the volume of air ventilating the perfused surfaces is

$$
\mathrm{V}_{\mathrm{T}}-\mathrm{V}_{\mathrm{D}}
$$

Thus the volume of air reaching the perfused surfaces of the lung per minute is

$$
\begin{gathered}
\left(V_{T}-V_{D}\right) f \\
\text { so that } \\
V_{A}=\left(V_{T}-V_{D}\right) f
\end{gathered}
$$

In practice the situation is complicated by the fact that not all alveoli are equally perfused. Those near the apex receive less blood than those at the base of the lung, which tend to be less well ventilated. (West 1962)

The ratio of ventilation/perfusion (V/O) varies widely through the lung, but averages about 0.9 for the normal individual (West 1965). Thus the effective or 
"physiological dead space" may exceed the volume of the conducting air passages.

The volume of the human anatomical dead space has been measured from the volume of the conducting air passages; Zuntz (1882) Loewy (1894), Nunn and his colleagues (1959) have reported values between 138 and $150 \mathrm{mls}$. on cadavers. Physiological dead space has been determined by gas washout techniques and has been found to increase with tidal volume from $7.0-8.0 \mathrm{~m} / \mathrm{s}$. per $100 \mathrm{mls}$. rise in tidal volume. (Asmusson and Neilson 1956, Jones and his colleagues 1966).

Ventilation is driven by a large number of factors among the most important being arterial oxygen and carbon dioxide tensions and $\mathrm{pH}$. An increase in ventilation occurs during the initial phase of exercise which is not accounted for by any of the above and respiration can be placed under conscious control, at least for short periods. It has occured to investigators that some of these mechanisms might be responsible for controlling depth of breathing while others influence only rate. Thus in 1919 Haldane, Meakins and Priestly concluded "The Effect of want of oxygen was to increase rate of respiration rather than depth, while carbon dioxide increased depth rather than rate". However, Dripps and Comroe disagreed and in 1947 wrote "The increase in respiration at all oxygen concentrations was achieved largely by an increase in the depth of breathing".

In 1966 Hey and his colleagues re-investigated the relationship between the respiratory variables tidal volume, minute volume and breathing frequency.

They found that if minute volume was plotted against tidal volume an approximately straight line relationship was obtained up to about half vital capacity. This line was of slope $\mathrm{m}$ and intercept $\mathrm{c}$ on the tidal volume axis, so that minute volume and tidal volume had the approximate relationship.

$$
\dot{V}_{\mathrm{e}}=\mathrm{m}\left(\mathrm{V}_{\mathrm{T}}-\mathrm{c}\right)
$$

The relationship occured at rest and when ventilation was stimulated by carbon dioxide and exercise. It was demonstrated to be unaffected by posture, a wide range of alveolar gas tensions, adrenaline, mild acidaemia and alkalosis. Analysis of data of Loeschcke and his colleagues (1953) demonstrated that the respiratory depressants morphine and mederidine were without effect, and of Cross and his colleagues (1954) that the relationship was unchanged by mild hypoxia.

Cotes and his colleagues (1970) confirmed the relationship in 18 racing cyclists, and found that they were able to describe the relationship by 2 intersecting straight lines. The first was as previously described by
Hey and his colleagues (1966) and the second parallel to the minute volume axis representing constant tidal volume. Analysis of the data of Gee, Vassalo and Gregg (1968) indicated that the relationship was not changed by breathing through a small fixed resistance.

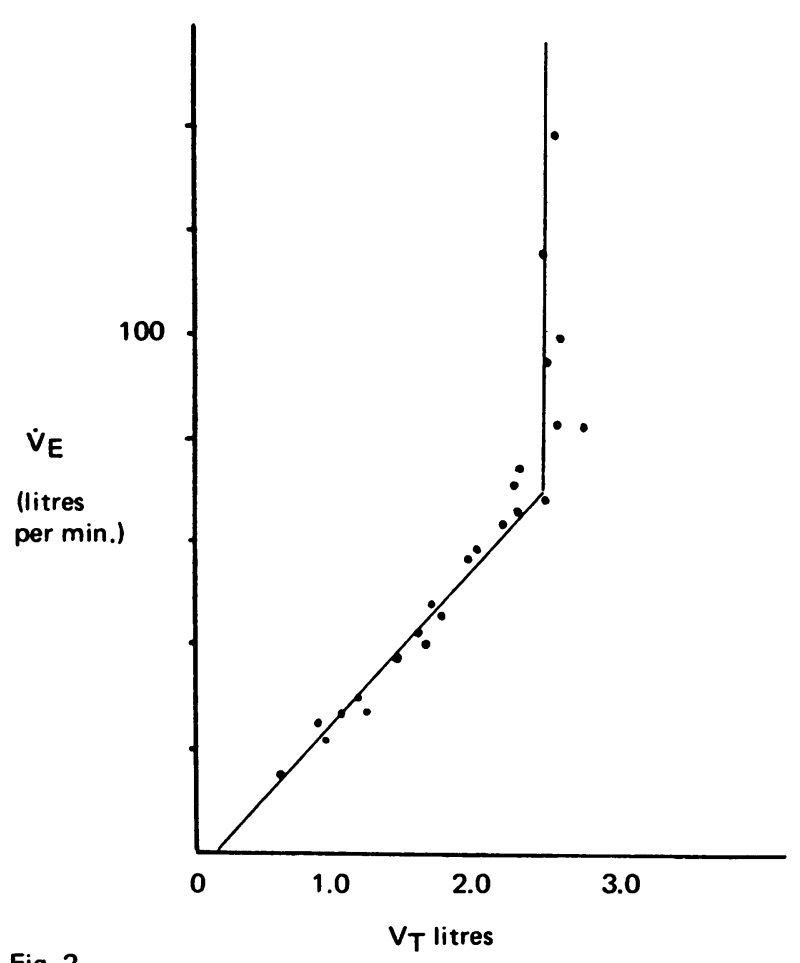

Fig. 2

This relationship is illustrated in figure $\mathbf{2}$ for one typical subject with computer drawn regression lines superimposed (Data from Kelman and Watson 1972).

Figure 3 shows the mean relationship of 6 subjects from Kelman and Watson (1972). In this figure a series of lines have been drawn indicating the breathing frequency. This illustrates that the increase in minute volume occurs through an increase in both tidal volume and breathing frequency.

Cotes and his colleagues (1970) found that the point of intersection of the 2 lines was clearly identifiable in 16 out of 18 of their subjects. A number of their subjects reported that they experienced the phenomenon of "second wind" at this point.

Circumstances in which the minute volume - tidal volume relationship may be modified

Hey and his colleagues reported that raising rectal 


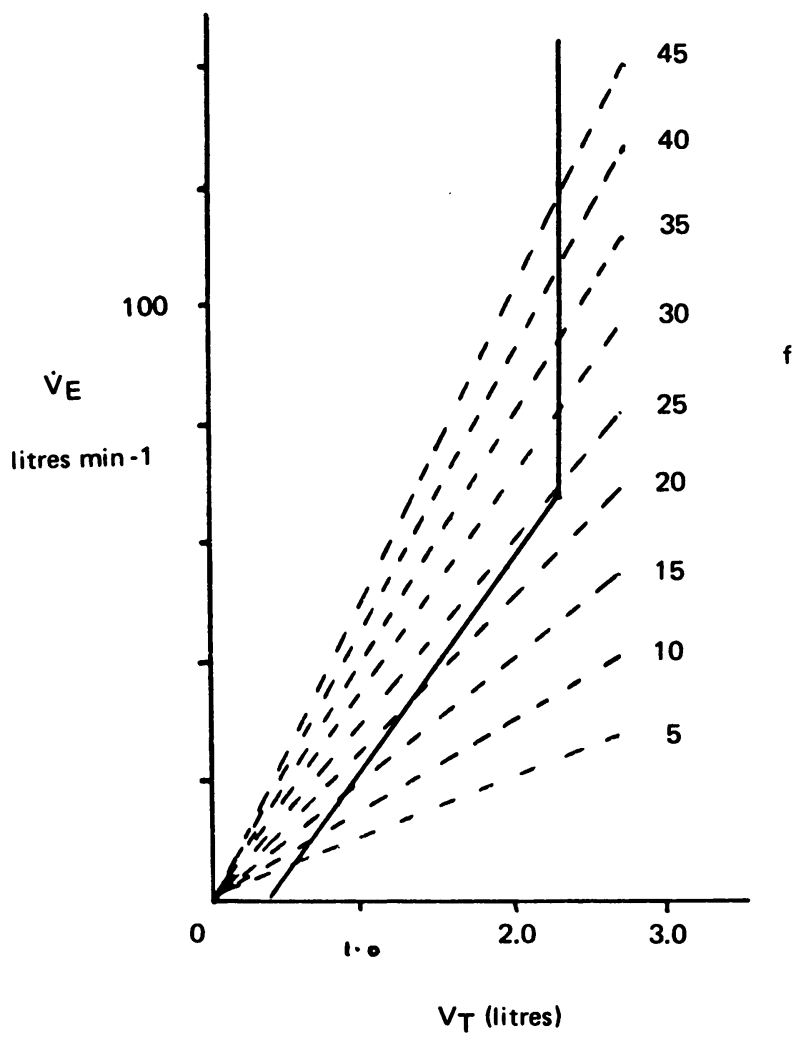

Fig. 3

temperature produced higher values of minute volume at a given tidal volume. The general nature of the relationship remained unchanged but the sloping line was displaced to the left. These workers produced the the increase in core temperature by means of a heated suit but temperature changes of a similar magnitude would be likely to occur during muscular exercise of moderately long duration.

Kelman and Watson (1972) investigated the effect of increasing the respiratory dead space on the minute volume/tidal volume relationship. They found that in these circumstances the relationship was displaced to the right as indicated in figure 4.

Since an increase in dead space results in a larger proportion of each breath failing to reach perfused surfaces of the lung, an increase in tidal volume would be expected to minimise the wasted ventilation.

$$
\begin{gathered}
\text { Useful ventilation }=V_{A}=\left(V_{T}-V_{D}\right) \cdot f \\
\text { Wasted ventilation }=V_{D} \cdot f \\
\text { Useful ventilation }=\frac{\left(V_{T}-V_{D}\right) f}{V_{E}} \\
\text { Total ventilation }
\end{gathered}
$$

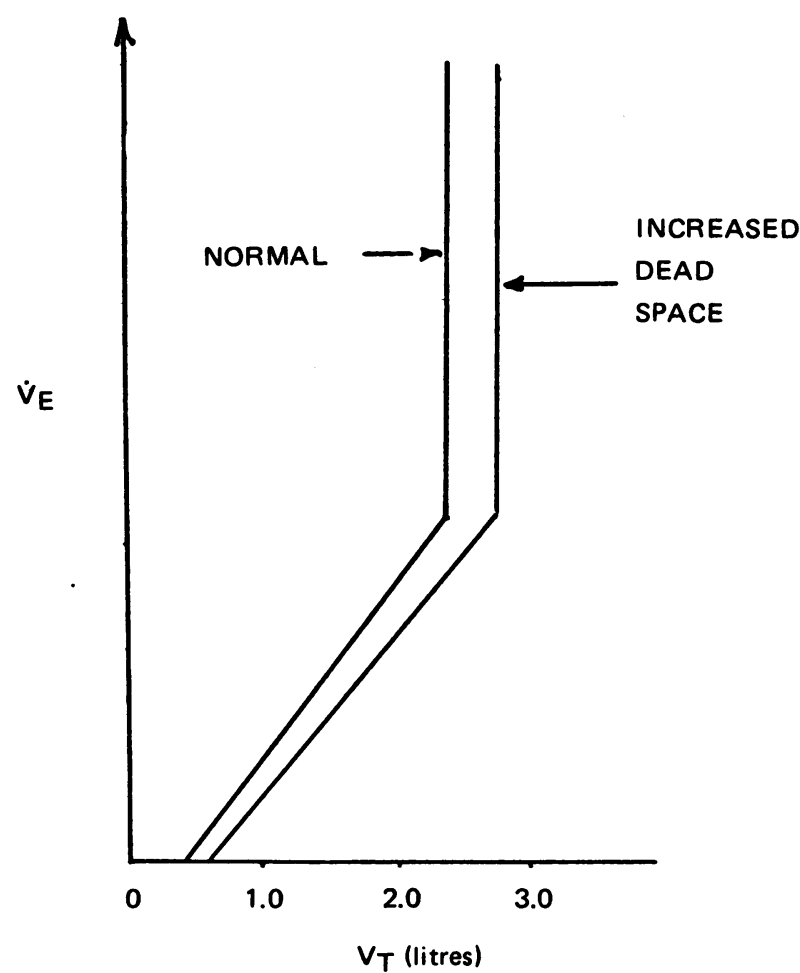

\section{Conclusions}

An increase in ventilation can be affected by an increase in both the depth and frequency of breathing. The relationship between these two factors has been investigated under a wide range of conditions and appears unaffected by whether ventilation is driven by exercise, hypercarbia or hypoxia. In all cases the increase in minute volume occurs through an increase in both tidal volume and breathing frequency, and the relationship between minute volume and tidal volume appears to be constant and approximately linear up to about half vital capacity. In many subjects the relationship may be represented by two intersecting straight lines, and it has been reported that "second wind" may be experienced near the point of intersection. Two factors may modify the slope of the line - increased core temperature and increased respiratory dead space. Both these factors may occasionally be experienced in sporting activities. Increased core temperature during prolonged heavy exercise and increased dead space when using external breathing apparatus such as in SCUBA diving. 


\section{REFERENCES}

ASMUSSEN, E. and M. NIELSON (1960) Acta.Physiol.Scand., 38, 1

COTES, J. E., G. R. JOHNSON, and A. McDONALD (1970) Breathing: Hering Breuer Centenary Ciba Symposium, p. 297, Churchill

CROSS, K. W., J. M. D. HOOPER, and J. M. LORD (1954) J.Physiol. 158, 1

DRIPPS, R. D. and J. H. COMROE (1947) Am.J.Physiol. 149, 277

GEE, J. B. L., B. C. VASSALLO and J. GREGG (1968) Am. Rev. Resp.Dis. 981003

HALDANE, J. S., J. C. MEAKINS and J. G. PRIESTLY (1919) J.Physiol. 52, 420

HEY, E. N., B. B. LLOYD, D. J. C. CUNNING, M. G. M. JUKES, D. P. G. BOLTON (1966) Respiratory Physiology, 1 193

JONES, N. L., G. J. R. McHARDY, A. NAIMARK, E. J. M. CAMPELL (1966) Clin.Science 31, 19

KELMAN, G. R. and A. W. S. WATSON (1972) J.Physiol. 227, 47-49p.

LOESCHCKE, H. H., A. SWEEL, R. H. KROUGH, and C. J. LAMBERTSON (1953) J. Pharmacol. 108376

LOEWY, A. (1894) Pflugers.Arch.ges Physiol., 58416

NUNN, J. F., E. M. J. CAMPELL, and B. W. PECKETT (1959) J.Applied Physiol., 14, 174

WEST, J. B. (1962) J.Applied Physiol., 17, 893

WEST, J. B., (1965) Ventilation/Blood flow and gas exchange, Blackwell, Oxford

ZUNTZ, N. (1882) Hermann's Handbuch Physiol, 4, 1 